\title{
Examining the Relationship between Borderline Personality Traits and the Level of Craving for Methamphetamine Use among Men and Women
}

Pirnia, $\mathrm{B}^{1 *}$, Asadi, $\mathrm{R}^{2}$

\section{ABSTRACT}

Objective: The present study is conducted with the aim of examining the relationship between borderline personality traits and the level of craving for use in individuals dependent to stimulant drugs. Methods: The study is descriptive and correlational. 114 male and female Methamphetamine users, who got the highest scores in Borderline Personality Questionnaire in screening stage, were selected and the craving for use was evaluated in them using Visual Index Scale of Assessing Craving for Use. Data were analyzed using independent t test and Pearson test. Findings: Results showed there is a positive significant relationship between borderline personality traits and the level of craving for use. Also, there is a significant difference between the severity of symptoms and craving for use and sex. That is, women scored higher in both components. Conclusion: The present findings can help to take measures in the field of addiction treatment and personality characteristics deserve to be considered in planning appropriate interventions.

Keywords: Borderline Personality Disorder, Craving For Drug Use, Drug Abuse, Methamphetamine, Addiction

Addiction is a comprehensive and one of the significant problems to be considered. A brief look at the statistics further pointed out the importance of this phenomenon. More than half of the incoming population in the prisons is drug users (Farnia, Ebrahimi, Shams, Zamani, 2010) and it is estimated that thirty-five million people worldwide consume methamphetamine (Degenhardt, 2012). The reports of the World Health Organization show that there are about two million drug addicts in the world and the highest incidence of addiction is in Iran with 8.2 percent (Rezai, Delaware, Najafi, 2011). Methamphetamine due to its growing has become a challenge in the health sector in Iran (Alammehrjerdi, Alasdair, Noroozi, 2013). Unfortunately, a dramatic spread

\footnotetext{
${ }^{1}$ PhD Student of Clinical Psychology, Departmnt Of Psycology, Faculty Of Humanities, University Of Science And Culture, Tehran, Iran.

${ }^{2}$ MA.S, Department of Psychology and Exceptional Education, Faculty of Psychology and Educational Sciences, Tehran University, Tehran, Iran.

*Corresponding Author

(C) 2015 I B Pirnia, R Asadi; licensee IJIP. This is an Open Access Research distributed under the terms of the Creative Commons Attribution License (http://creativecommons.org/licenses/by/2.0), which permits unrestricted use, distribution, and reproduction in any Medium, provided the original work is properly cited.
} 


\section{Examining the Relationship between Borderline Personality Traits and the Level of Craving for Methamphetamine Use among Men and Women}

of methamphetamine use in many countries of the world has been observed in recent years (He, Xie, Tao, Su, Wu, Zou et al, 2013).

In Iran, the use of methamphetamine has increased 150 times between 2008- 2005 (Radfar, Rawson, 2014). With the increase in Iran's domestic production of methamphetamine laboratory in the last five years, the price has been declined up to one-fifth and according to the unofficial statistics its use in Iran is in the second or third place most widely used material (Shariat, Elahi, 2010).

Methamphetamine is associated with the release of neurotransmitters adrenaline, dopamine and serotonin (Collins, Schlosburg, Lockner, Bremer, Ellis et al, 2014) and affects the central nervous system (Lea, Mao, Bath, Prestage, Zablotska et al, 2013; Volkow, Fowler, Wang, Shumay, Telang et al, 2010). One of the main questions for psychologists and researchers in the field of addiction is that if certain personality traits differentiate the addicts from ordinary people and if addiction is rooted in more fundamental structures. And whether the traits and characteristics are due to the changes have been created due to drug use for a long time or they were present before drug abuse.

According to some researchers, the personality traits and attributes that reported resulting in alcoholics were perhaps one of the first scientific attempts to describe the addicted personality. Lack of emotional and biased attributes to those who have a role in a person's life, low tolerance of failure, guilt and confusion of sexual roles are among the features that have been mentioned in various studies. According to Fischer, Elias and Ritz (First, Spitzer, Gibbon, Williams et al, 2002), two personality traits of high neuroticism and low conscientiousness play an important role in infection and frequent recurrence after treatment in these patients.

Saduck and colleagues in the Kaplan Comprehensive Textbook of Psychiatry have stated that in various studies, about 30 and 60 percent of patients with drug abuse had diagnostic criteria for antisocial personality disorder, while the figure is 2 to 3 percent in the general population (Kaplan, Sadock's, 2001). Two antisocial personality disorder and borderline role in the process of creating drug addiction and repeated relapse after remission has been noted by the clinicians. In terms of psychopathology, there is a close relationship between borderline personality disorder and drug abuse exists (Grant, Chou, Goldstein, Huang, Stinson, 2008) and drug abuses aggravate symptoms in these people. The prevalence of borderline personality disorder have been reported about 5-5.9 per cent in the general population (Zanarini, Horwood, Wolke, Waylen, Fitzmaurice, Grant, 2011) and 25-15\% in clinical populations (Gunderson, 2009). Borderline personality disorder is a B category disorder. Looking at the clusters of personality disorders we find that cluster $\mathrm{B}$ has the highest correlation with drug abuse disorder (Daly, 2005), antisocial personality disorder and narcissistic (Grant et al, 2008). 


\section{Examining the Relationship between Borderline Personality Traits and the Level of Craving for Methamphetamine Use among Men and Women}

This category of disorders is expressed with impulsivity, transient emotions and self-destruction (Narud, Mykletun, Dahl, 2005). Other symptoms of this disorder include rapid change scenarios in temperament, impulsivity and self-harm behavior, unstable self-perception, unstable and intense interpersonal relationships and physical and sexual abuse (Wingenfeld, Rullkoetter, Mensebach, Beblo, Mertens et al, 2009). People with borderline signs (or characters), although have a number of features, but because their scores are lower than the cut-off point, they cannot be distinguished as having borderline personality disorder (Millon, 2004). There is a strong relationship between drug abuse and borderline personality disorder (Skodol, Gunderson, Pfohl, 2002). Several studies have approved the correlation between borderline personality disorder and drug abuse (Trull, Sher, Minks-Brown, Durbin, Burr, 2000).

The prevalence of drug abuse in patients with borderline personality has been reported 0.39 to 0.84 with the mean of 0.67 (Zanarini, Frankenburg, Dubo, Sickel, Trikha et al, 2014). It is believed that the high correlation between borderline personality disorder and drug abuse is due to a causal relationship (Verheull, Ball, vanden Brink, 1997). In one study, 32 percent of patients taking cocaine (Weiss, Mirin, Griffin, Gunderson, Hufford, 1993), 13\% of those participating in alcohol rehab program and $17 \%$ of patients with multiple usage patterns (Nace, Saxon, Shore, 1983) were diagnosed with borderline personality. In the study of Links and colleagues (Links, Heslegrave, Reekum, 1999), it was shown that these two groups were not significantly different from each other in terms of social harmony, affection, psychotic symptoms, interpersonal problems and functional problems. In addition, the indicators of impulsivity explain part of the relationship between borderline personality disorder and drug abuse (Skodol, Gunderson, Pfohl, 2002). Biologically, people with borderline personality disorder are born with a primary biological vulnerability in emotion regulation (Linehan, 1993) and inability to manage emotions play a role in the onset of drug abuse (parker, Taylor, Eastabrook, Schell, Wood, 2008). Neuropsychological studies indicate damage in executive functions, decision-making and tendency to cognitive distortions in patients with borderline personality disorder (Mak, Lam, 2013) which are mainly driven by the frontal lobe, the part that is responsible for the phenomenon of craving in these patients. The concept of craving is one of the most important cognitive foundations of knowledge for drug abuse and it can be considered as the most important elements of drug abuse (Ekhtiari, Mokri, Abharian, Daneshmand, Tabatabaii, Alammehrgerdy, 2008).

In the process of treating therapy after the addicted person reaches avoidance, temptation and a penchant for re-using experience and gradually reduced over time but rarely disappears altogether and is the cause of treatment failure (Abrams, 2000). Relapse is the result of an indifference to the future consequences of drug use and reflects the defective decision-making process (Bechara, Dolan, Denburg, Hindes, Anderson, Nathan, 2001), which represents a failure in the frontal cortex of these patients (Goldstein, Volkow, 2002). Despite knowing about the consequences of traumatic abuse, greed is considered as a subjective or conscious experience 


\section{Examining the Relationship between Borderline Personality Traits and the Level of Craving for Methamphetamine Use among Men and Women}

(Ekhtiari, 2008) and from among the consequences of unmet craving; one can point to the loss of appetite, weakness, insomnia, aggression and depression (Avants, Margolin, Kosten, Cooney, 1995).

Craving is affected by the scenarios, associated stimuli and demographic characteristics (Verheal, Brink, Greelings, 1999).

Personality differences reflect the relationship between personality traits and craving in alcohol and cocaine consumers (Zilberman, Tavares, El-Guebaly, 2003). According to what mentioned above, people with borderline personality traits can be considered as those tending to addiction. These characteristics can consequently call craving and subsequent faults in these patients. Therefore, correlation of the personality traits and craving are clinically noteworthy.

Given the importance of this relationship, the present study tries to examine these two structures as the relationship between borderline personality features and the index of consumer craving in male and female users of methamphetamine.

\section{METHODOLOGY}

The present study is a descriptive correlational survey. The study population includes all men and women addicted to methamphetamine that visited to one of the rehab centers during the spring of 2015 and were treated on the basis of psychiatric diagnosis using Structured Clinical Interview for DSM- IV by a clinical psychologist and were dragonized to have drug abuse and were treated at this center. After the implementation of screening, 114 of the patients (73 males and 41 females) who had the highest and lowest scores according to a given cut-off point were selected from among the population, and then completed the craving questionnaire. Ethical standards of the research included the privacy of the participants, protection of their welfare and comfort, the written informed consent about participating in the sessions and the possibility of leaving the research at any stage of the study was provided for all the participants. The inclusion criteria were: 1) age range of 25-45 years old 2) Minimum level of education, ability to read and write 3) addiction experience between 5-15 years 4) the amount of usage (between 0.5 to $1 \mathrm{~g}$ per day). Exclusion criteria also included: 1) dependence on other drugs at the same time 2) retardation or severe mental disorders 3) severe physical illness. In addition, two groups were homogenized in terms of age, social class, severance and similar dose of methamphetamine dependence and the possible effects of these variables were removed on the dependent variable. In this study, a demographic questionnaire, the Structured Clinical Interview for DSM IV.DSM(SCID) and video questionnaire were used to measure craving.

\section{RESEARCH INSTRUMENTS}

In this study, a demographic questionnaire, Structured Clinical Interview, borderline personality questionnaire and a visual indicator of measuring craving was used. 


\section{Examining the Relationship between Borderline Personality Traits and the Level of Craving for Methamphetamine Use among Men and Women}

\section{-Demographic questionnaire}

Demographic questionnaire was used by the researcher to collect personal information such as age, education, socioeconomic status, history of illness, history of drug use and treatment duration.

\section{-Structured Clinical Interview}

Structured Clinical Interview for disorders (DSM IV (SCID)) is a clinical interview used for the diagnosis of the Axis I disorder based on DSM - IV. Inter-rater reliability for SCID has been reported as 0.60 (First et al, 2002). Diagnostic agreement of this instrument in Persian for most specific and general diagnosis has been proper with higher reliability of 0.60 . The Kappa coefficient for the entire current detection and diagnosis obtained during life has been 0.52 and 0.55, respectively (Sharifi, Assadi, Mohammadi, Amini, Kaviani, 2009).

\section{-Borderline Personality Inventory (BPI)}

Borderline Personality Inventory (BPI) has been designed based on Kernberg's concept of borderline personality organization and diagnostic criteria for DSM - IV. The questionnaire has four subscales of identity diffusion, the impaired primitive defense mechanisms, reality testing and fear of intimacy. This questionnaire has been validated by Mohammadzadeh and Rezaei (Mohammadzadeh, Rezaei, 2011) on the Iranian sample. Accordingly, the concurrent validity, internal consistency of the subscales with the entire scale and with each other was $0.70,0.80$ and 0.71 , respectively and test-retest, internal consistency and split-half reliability of it was 0.80 , 0.83 and 0.85 , respectively. Therefore, proper validity and reliability have been reported for this scale.

\section{-Video index of measuring craving}

Video index of measuring craving with the use of visual stimuli causing the craving is a tool to evaluate craving in addicts. The test contains 12 images, two of which are foil. After presenting images, the patients are asked to rate themselves on a scale of craving calls at 100-0 specify. This amount can be used on a continuum from "no" to "very high". This test was made by Ekhteyari et al (Ekhtiari et al, 2008) in 1998 and the performance and efficiency has been confirmed as Five Visual assessment of craving in opioid addicts.

\section{RESULTS}

The collected data were analyzed using the indices of mean, standard deviation, t-test, Pearson Correlation Coefficient and by help of SPSS software version 18.0. The results of data analysis are shown in the tables below. Table 1 shows the mean and standard deviation of the participants in borderline personality and carving for use. From among 114 participants in the study, 73 were 


\section{Examining the Relationship between Borderline Personality Traits and the Level of Craving for Methamphetamine Use among Men and Women}

male and 41 were female. The age range of the female participants was 26 to 37 years old with a mean of 31 and the age range of the male participants was 25 to 34 years old with the mean of 34. Distribution of the participants based on marital status and educational level is presented in the table 1 . The results in Table 2 indicate that borderline personality traits are associated with craving so that the borderline personality symptoms in women were more than men. In addition, there were statistically significant differences in the index of craving in male and female participants. According to the data in Table 1, there were significant differences in female borderline personality traits scores with scores of men in this indicator. There was also a significant difference between two genders in terms of carving. On the other hand there was a significant relationship between the two components of craving and the borderline personality, $(\mathrm{r}=026, \mathrm{p}=0.001)$. In addition, there was a significant relationship between the time to avoid drug and craving, $(\mathrm{r}=-0.14, \mathrm{p}=0.05)$. Thus, both borderline personality index and the craving in women was more than those in men.

\section{CONCLUSION}

This study aimed to investigate the relationship between personality traits and craving for methamphetamine-dependent individuals. The results showed that there was a relationship between these two components. Literature review was in line with the results of this research. However, no similar study was found in the literature review on the issue but the previous research has confirmed the relationship between borderline personality disorder and drug abuse. In the study of Tsarina and colleagues investigated the personal traits of those consuming cigarette marijuana, cocaine and heroin. Smokers had high scores on the neurotic index and obtained low scores on the duty components. Consumers of marijuana obtained high scores on openness to new experiences, but their neurotic scores was at average level and cocaine and heroin consumers had similar profile and both obtained high scores on neuroticism and low scores on duty. The studies confirmed that there was a relationship between neuroticism and impulsivity characteristic of opioid addicts (Powell, Gray, Bradley, Kasvikis, Strang et al, 1990) and also there was a positive correlation between neuroticism and introversion with craving in alcohol-dependent individuals (McCusker, Brown, 1991). Carving for drug (Millon, 1996) and poor emotional regulation (Wingenfeld et al, 2009) can be enumerated as the obvious traits of borderline personality disorder. Since the emotion structure is one of the important component in terms of the etiology of addiction, people with high emotional control ability, through the use of appropriate coping strategies, show more resistance to the drug abuse (Trinidad, Johnson, 2002), However, low levels of emotional control are associated with drug abuse (Doran, McChargue, Cohen, 2007). Patients with borderline personality disorder regulate their own emotional levels often through radical strategies (Klonsky, Muehlenkamp, 2007) and this process is defective in emotion regulation is related with a tendency to drug and alcohol (Cyders, Flory, Rainer, Smith, 2009; McCauley, Calhoun, 2008; Rolison, Scherman, 2002). In a study, Storemark and colleagues (Stormark, Laberg, Nordby, Hugdahl, 2000) in the form of cognitive therapy, with the goal of controlling craving in alcohol-dependent individuals, attempted to control their desire 


\section{Examining the Relationship between Borderline Personality Traits and the Level of Craving for Methamphetamine Use among Men and Women}

in the face of provocative stimuli. In this study, the incidence of carving in subjects showed a significant negative correlation with duration of abstinence and consequently, the age of the subjects. This finding was in line with the findings of the present study and findings of the study by Zilbermann et al (Zilberman et al, 2003). Ekhteyari (2008) in a study found that personality trait was an important factor in the amount of consumption and demographic factors were the predictive component in the craving. In a study, the craving and its relationship with mood periods was examined (Schlauch, Gwynn-Shapiro, Stasiewicz, Molnar, Lang, 2013). The results showed that people with high levels of negative emotions in the face of provocative clues showed more carving while the positive emotions were associated with avoiding these stimuli. Due to importance of craving, worth mentioning studies were done about the role of research in dependence relapse (Ekhteyari, 2008; Mokri, Ekhtiari, Norozi, Farnam, Ehterami, Meshkini, 2008; Hassani Abharian, Ekhtiari, 2008). Zilbermann and colleagues (Zilberman et al, 2003) in a study examined the relationship between personality traits and craving in alcohol and cocaine consumers. Their findings indicated that there was a relationship between these two variables. Varhill et al (Verheal et al, 1999) also in their study examined the important role of personality differences in the craving. By examining responses to stimuli craving, they found that there was a relationship between the intensity of craving and personality traits. In line with these findings, Paul, Bradley and Gray (Powell, Bradley, Gray, 1992) in a study examined the relationship between impulsivity and craving in opiate addicts. This study examined the relationship between borderline personality traits and craving index among the methamphetamine dependent male and female. The findings in the research in line with the literature showed the relationship between the two. There was a significant negative relationship between two indices of avoiding and the craving in line with previous research. In addition, the index of the border personality traits and craving of women showed a significant difference, which indicated the abundance of these two indicators in the women's sample. One of the difficulties of this research is the limitation on the cloning. Further, the research conducted in this area by examining consumer opioids could be targets for future research.

\section{LIMITATION}

The findings of the study had several limitations. The most significant of these restrictions were: (1) due to the small sample size, the findings should be interpreted as preliminary results; and this condition has significantly limited the reliability and effect of statistics; (2) the crosssectional nature of the study limits the overall conclusion and comprehensive forecast (3) using a self-report assessment in sensitive subjects often tend to create a favorable social image and thus, using self-reporting is associated with possible bias.

\section{Conflict of Interests}

The Authors have no conflict of interest.

\section{Authors' contribution}




\section{Examining the Relationship between Borderline Personality Traits and the Level of Craving for Methamphetamine Use among Men and Women}

Pirnia B were responsible for the study concept, design and contributed to the acquisition of experience data and data analysis and interpretation of findings, Asadi R provided critical revision of the manuscript for important intellectual content. Pirnia B critically reviewed content and approved final version for publication.

\section{Acknowledgments}

The researcher appreciates all those who participated in the study and helped to facilitate the research process.

\section{REFERENCES}

Abrams, D. B. (2000). Transdisciplinary concepts and measures of craving: commentary and future directions. Addiction, 95(8s2), 237-246.

Alammehrjerdi A, Alasdair MB, Noroozi A. (2013). Methamphetamine-associated psychosis: a new health challenge in Iran. DARU Journal of pharmaceutical Sciences. 2013; 21(1): 22-31.

Avants, S. K., Margolin, A., Kosten, T. R., \& Cooney, N. L. (1995). Differences between responders and nonresponders to cocaine cues in the laboratory. Addictive Behaviors, 20(2), 215-224.

Bechara, A., Dolan, S., Denburg, N., Hindes, A., Anderson, S. W., \& Nathan, P. E. (2001). Decision-making deficits, linked to a dysfunctional ventromedial prefrontal cortex, revealed in alcohol and stimulant abusers. Neuropsychologia, 39(4), 376-389.

Collins, K. C., Schlosburg, J. E., Lockner, J. W., Bremer, P. T., Ellis, B. A., \& Janda, K. D. (2014). Lipid tucaresol as an adjuvant for methamphetamine vaccine development. Chem. Commun., 50(31), 4079-4081.

Cyders, M. A., Flory, K., Rainer, S., \& Smith, G. T. (2009). The role of personality dispositions to risky behavior in predicting first-year college drinking. Addiction, 104(2), 193-202.

Daly, C. (2005). Managing the Dually Diagnosed Patient-Current Issues and Clinical Approaches, 2nd edn. By D. O'Connell and E. Beyer, The Haworth Press, New York.£ 33.00. 352 pgs. ISBN 078900877 7. Alcohol and Alcoholism, 40(2), 157-158.

Degenhardt LHW. (2012). Extent of illicit drug use and dependence, and their contribution to the global burden of disease. Lancet. 379:55-70.

Doran, N., McChargue, D., \& Cohen, L. (2007). Impulsivity and the reinforcing value of cigarette smoking. Addictive behaviors, 32(1), 90-98.

Ekhtiari, H. (2008). Neurocognitive basis of drug craving; an overview to evalvation and intervention methods. Quarterly Journal of Addiction, 1(3), 90-6.

Ekhtiari, H., Mokri, A., Abharian, P., Daneshmand, R., Tabatabaii, H., \& Alammehrgerdy, Z. (2008). The evaluation of neurocognitive aspects of cue-induced craving: by using fMRI, subjective psychological tests and objective cognitive tasks in heroin smoker before and after one month abstinence. Quarterly Journal of Addiction, 2(2), 21-28. 


\section{Examining the Relationship between Borderline Personality Traits and the Level of Craving for Methamphetamine Use among Men and Women}

Farnia, M., Ebrahimi, B., Shams, A., \& Zamani, S. (2010). Scaling up methadone maintenance treatment for opioid-dependent prisoners in Iran. International Journal of Drug Policy, 21(5), 422-424.

First, M. B., Spitzer, R. L., Gibbon, M., \& Williams, J. B. W. New York: Biometrics Research, New York State Psychiatric Institute; 2002. Structured Clinical Interview for DSM-IV-TR Axis I Disorders, Research Version, Patient Edition.(SCID-I/P).

Fisher, L. A., Elias, J. W., \& Ritz, K. (1998). Predicting relapse to substance abuse as a function of personality dimensions. Alcoholism: Clinical and Experimental Research, 22(5), 1041-1047.

Goldstein, R. Z., \& Volkow, N. D. (2002). Drug addiction and its underlying neurobiological basis: neuroimaging evidence for the involvement of the frontal cortex. American Journal of Psychiatry, 159(10), 1642-1652.

Grant, B. F., Chou, S. P., Goldstein, R. B., Huang, B., Stinson, F. S., Saha, T. D., ... \& Ruan, W. J. (2008). Prevalence, correlates, disability, and comorbidity of DSM-IV borderline personality disorder: results from the Wave 2 National Epidemiologic Survey on Alcohol and Related Conditions. The Journal of clinical psychiatry, 69(4), 533.

Gunderson, J. G. (2009). Borderline personality disorder: ontogeny of a diagnosis. The American journal of psychiatry, 166(5), 530.

Hassani Abharian, P., \& Ekhtiari, H. (2008). Attentional bias and its applications in evaluation of drug craving as a complex emotional state. Quarterly Journal of Addiction, 2(2), 49-62.

He J, Xie Y, Tao J, Su H, Wu W, Zou S, et al. (2013). Gender differences in socio- demographic and clinical characteristics of methamphetamine inpatients in a Chinese population. Drug Alcohol Dep. 130(1-3):94-100.

Kaplan., Sadock's(2001). Synopsis of Psychiatry Behavioral Sciences. 10th ed.

Klonsky, E. D., \& Muehlenkamp, J. J. (2007). Self-injury: A research review for the practitioner. Journal of clinical psychology, 63(11), 1045-1056.

Lea, T., Mao, L., Bath, N., Prestage, G., Zablotska, I., de Wit, J., et al. (2013). Injecting drug use among gay and bisexual men in Sydney: prevalence and associations with sexual risk practices and HIV and hepatitis C infection. AIDS Behav. 17, 1344-1351.

Linehan, M. (1993). Cognitive-behavioral treatment of borderline personality disorder. Guilford Press.

Links, P. S., Heslegrave, R., \& Reekum, R. V. (1999). Impulsivity: core aspect of borderline personality disorder. Journal of personality disorders, 13(1), 1-9.

Mak, A. D., \& Lam, L. C. (2013). Neurocognitive profiles of people with borderline personality disorder. Current opinion in psychiatry, 26(1), 90-96.

McCauley, J. L., \& Calhoun, K. S. (2008). Faulty perceptions? The impact of binge drinking history on college women's perceived rape resistance efficacy. Addictive behaviors, 33(12), 1540-1545.

McCusker, C. G., \& Brown, K. (1991). The cue-responsivity phenomenon in dependent drinkers:'personality'vulnerability and anxiety as intervening variables. British Journal of Addiction, 86(7), 905-912. 


\section{Examining the Relationship between Borderline Personality Traits and the Level of Craving for Methamphetamine Use among Men and Women}

Millon, T., (2004). Personality Disorders in Modern Life, New Jersey: Willy.

Millon, T. (1996). Personality and psychopathology: Building a clinical science: Selected papers of Theodore Millon. John Wiley \& Sons Incorporated.

Mohammadzadeh, A., \& Rezaei, A. (2011). Validation of the borderline personality inventory in Iran. $J$ behav Sci, 5(3), 269-77.

Mokri A, Ekhtiari H, Norozi A, Farnam R, Ehterami M, Meshkini B. (2008). [An introduction to INCAS substance abuse profile (ISAP) (Persian)]. Quarterly Journal of Addiction, 1(4):16-23.

Nace, E. P., Saxon, J. J., \& Shore, N. (1983). A comparison of borderline and nonborderline alcoholic patients. Archives of General Psychiatry, 40(1), 54-56.

Narud, K., Mykletun, A., \& Dahl, A. A. (2005). Therapists' handling of patients with cluster B personality disorders in individual psychotherapy. Comprehensive psychiatry, 46(3), 186-191.

Paris, J. (2009). The treatment of borderline personality disorder: implications of research on diagnosis, etiology, and outcome. Annual Review of Clinical Psychology, 5, 277-290.

parker, J.D., Taylor, R.N., Eastabrook, J.M., Schell, S.L. \& Wood, L.M. (2008). Problem gambling in adolescence: Relationshupes with internet misuse, gaming abuse and emotional intelligence. Personality and individual differences, 45, 174-180.

Powell, J., Bradley, B., \& Gray, J. (1992). Classical conditioning and cognitive determinants of subjective craving for opiates: an investigation of their relative contributions. British Journal of Addiction, 87(8), 1133-1144.

Powell, J., Gray, J. A., Bradley, B. P., Kasvikis, Y., Strang, J., Barratt, L., \& Marks, I. (1990). The effects of exposure to drug-related cues in detoxified opiate addicts: a theoretical review and some new data. Addictive Behaviors, 15(4), 339-354.

Radfar, S. R., \& Rawson, R. A. (2014). Current research on methamphetamine: Epidemiology, medical and psychiatric effects, treatment, and harm reduction efforts. Addiction and Health, 6(3-4), 146-154.

Rezai Am, Delaware A, Najafi M. (2012). [Construction and validation of a questionnaire measuring attitudes toward drugs in junior high school students in the country]. Journal of Etiyad pazhohi, 6(24): 37-54. [Persian].

Rolison, M. R., \& Scherman, A. (2002). Factors influencing adolescents' decisions to engage in risk-taking behavior. Adolescence.

Schlauch, R. C., Gwynn-Shapiro, D., Stasiewicz, P. R., Molnar, D. S., \& Lang, A. R. (2013). Affect and craving: Positive and negative affect are differentially associated with approach and avoidance inclinations. Addictive behaviors, 38(4), 1970-1979.

Skodol, A.E., Gunderson, J.G., Pfohl, B., (2002). The Borderline Diagnosis: Psychopathology, Comorbidity, Personality structure. Biological Psychiatry, 51,936-950.

Skodol, A. E., Gunderson, J. G., Pfohl, B., Widiger, T. A., Livesley, W. J., \& Siever, L. J. (2002). The borderline diagnosis I: psychopathology, comorbidity, and personaltity structure. Biological psychiatry, 51(12), 936-950. 


\section{Examining the Relationship between Borderline Personality Traits and the Level of Craving for Methamphetamine Use among Men and Women}

Shariat, S. V., \& Elahi, A. (2010). Symptoms and course of psychosis after methamphetamine abuse: one-year follow-up of a case. Primary care companion to the Journal of clinical psychiatry, 12(5).

Sharifi, V., Assadi, S. M., Mohammadi, M. R., Amini, H., Kaviani, H., Semnani, Y., ... \& Jalali, M. (2009). A persian translation of the structured clinical interview for diagnostic and statistical manual of mental disorders: psychometric properties. Comprehensive psychiatry, 50(1), 86-91.

Stormark, K. M., Laberg, J. C., Nordby, H., \& Hugdahl, K. (2000). Alcoholics' selective attention to alcohol stimuli: automated processing?. Journal of Studies on Alcohol and Drugs, 61(1), 18.

Trull, T. J., Sher, K. J., Minks-Brown, C., Durbin, J., \& Burr, R. (2000). Borderline personality disorder and substance use disorders: A review and integration. Clinical psychology review, 20(2), 235-253.

Trinidad, D. R., \& Johnson, C. A. (2002). The association between emotional intelligence and early adolescent tobacco and alcohol use. Personality and individual differences, 32(1), 95105.

Verheal, R., Brink, W. V. D., \& Greelings, P. A. (1999). A three-pathway psychobiological of carving for alcohol. Alcohol and Alcoholism, 34, 197-222.

Verheull R, Ball SA \& vanden Brink W. (1997). Substance abuse and personality disorders. In H.R. Kranzler \& B.J.. Rounsaville (Eds), Dual diagnosis and treatment; Substance abuse andcomorbid medical and psychiatricpsychiatric disorders. New York: Marcel Dekker, 317-364.

Volkow, N D., Fowler, JS, Wang, G-J., Shumay, E, Telang, F., Thanos, P. K., et al. (2010). Distribution and pharmacokinetics of methamphetamine in the human body: clinical implications.

Weiss, R. D., Mirin, S. M., Griffin, M. L., Gunderson, J. G., \& Hufford, C. (1993). Personality disorders in cocaine dependence. Comprehensive Psychiatry, 34(3), 145-149.

Wingenfeld, K., Rullkoetter, N., Mensebach, C., Beblo, T., Mertens, M., Kreisel, S., ... \& Woermann, F. G. (2009). Neural correlates of the individual emotional Stroop in borderline personality disorder. Psychoneuroendocrinology, 34(4), 571-586.

Zanarini, M. C. (1993). Borderline personality disorder as an impulse spectrum disorder. Borderline personality disorder: Etiology and treatment, 67-86.

Zanarini, M. C., Horwood, J., Wolke, D., Waylen, A., Fitzmaurice, G., \& Grant, B. F. (2011). Prevalence of DSM-IV borderline personality disorder in two community samples: 6,330 English 11-year-olds and 34,653 American adults. Journal of personality disorders, 25(5), 607-619.

Zanarini, M. C., Frankenburg, F. R., Dubo, E. D., Sickel, A. E., Trikha, A., Levin, A., \& Reynolds, V. (2014). Axis I comorbidity of borderline personality disorder. 
Examining the Relationship between Borderline Personality Traits and the Level of Craving for Methamphetamine Use among Men and Women

Zilberman, M. L., Tavares, H., \& El-Guebaly, N. (2003). Relationship between craving and personality in treatment-seeking women with substance-related disorders. BMC psychiatry, 3(1), 1 .

Table 1: distribution of the participants in the two groups separated based on education and marital status

\begin{tabular}{rlrrrr} 
frequency & $\begin{array}{l}\text { High } \\
\text { degree }\end{array}$ & $\begin{array}{r}\text { school } \\
\text { and } \\
\text { lower }\end{array}$ & $\begin{array}{r}\text { Bachelor } \\
\text { degree }\end{array}$ & $\begin{array}{r}\text { single } \\
\text { and } \\
\text { higher }\end{array}$ & married \\
\cline { 2 - 6 } number & 75 & 39 & 36 & 78 \\
percent & $65 / 8$ & $34 / 2$ & $31 / 26$ & $68 / 74$
\end{tabular}

Table 2: comparison of the scores for borderline personality and carving for drug abuse based on gender variable male female df Sig. $\mathbf{T}$

\begin{tabular}{rccccc}
\hline $\begin{array}{c}\text { Borderline } \\
\text { personality }\end{array}$ & $18 / 19 \pm 1 / 69$ & $54 / 13 \pm 3 / 24$ & 114 & $0 / 03$ & $3 / 09$ \\
\hline $\begin{array}{r}\text { Carving for } \\
\text { drug abuse }\end{array}$ & $17 / 94 \pm 1 / 35$ & $18 / 02 \pm 1 / 37$ & 114 & $0 / 01$ & $-3 / 34$ \\
\hline
\end{tabular}

Authors, including:

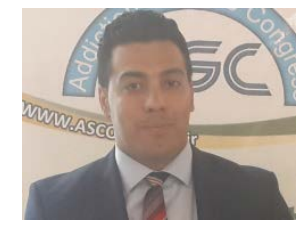

Bijan Pirnia, addiction researcher

PhD Student of Clinical Psychology, University of Science and Culture, Tehran, IRAN

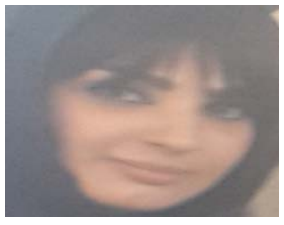

Razieh Asadi

MA.S, Department of Psychology and Exceptional Education, Faculty of Psychology and Educational Sciences, Tehran University, Tehran, IRAN 